\title{
"Gosto do deslocamento": espaços urbanos e testes de poesia em Marília Garcia
}

\author{
Jailma da Costa Ferreira*
}

\section{Resumo}

Discutiremos neste artigo acerca dos deslocamentos da voz poética na poesia de Marília Garcia, a partir de uma leitura crítica e analítica dos poemas "pelos grandes bulevares" e "noite americana", ambos do livro Câmera lenta (2017). Descentralizados de um eu, seus textos são compostos a partir dos acidentes, dos (des)encontros que acontecem e são provocados no (e pelo) espaço urbano. Desse modo, queremos compreender de que forma os aspectos que compõem esse espaço contribuem para a produção de singularidades e dos movimentos para fora do eu em sua poesia, considerando que esta realiza-se em diálogo com a vida urbana, com a observação vagarosa das situações que fazem parte desse meio. Em vista disso, apontamos alguns conceitos teóricos que embasam este estudo, a saber: Magalhães (2017), sobre os deslocamentos do eu; Reis (2015), a respeito dos testes que Marília faz em sua poesia; Busato (2015), acerca da relação dos sujeitos com o espaço urbano; entre outros.

Palavras-chave: Poesia brasileira contemporânea. Deslocamentos. Voz poética. Marília Garcia.

* Mestre em Literatura e Interculturalidade, pela Universidade Federal da Paraíba (UFPB). Atualmente desenvolve pesquisa no âmbito da poesia brasileira contemporânea. 


\title{
"Taste of Displacement": Urban Spaces and Poetry Tests in Marília garcia
}

\begin{abstract}
We will discuss in this article about the displacement of the poetic voice in the poetry of Marília Garcia, from a critical and analytical reading of the poems "pelos grandes bulevares" and "noite americana", both from the book Câmera lenta (2017). Decentralized from a self, his texts are composed from accidents, from (un) encounters that happen and are provoked in (and by) urban space. In this way, we want to understand how the aspects that make up this space contribute to the production of singularities and movements outside the self in his poetry, considering that this takes place in dialogue with urban life, with the slow observation of situations that are part of that medium. In view of this, we point out some theoretical concepts that support this study, namely: Magalhães (2017), about the displacements of the self; Reis (2015), regarding the tests that Marília does in her poetry; Busato (2015), about the subjects' relationship with the urban space; among others.
\end{abstract}

Keywords: Contemporary Brazilian poetry. Displacements. Poetic voice. Marília Garcia.

Recebido em: 30/09/2020 // Aceito em: 05/12/2020 


\section{Introdução}

Poeta, tradutora e editora, Marília Garcia nasceu em 1979, na cidade do Rio de Janeiro/RJ, graduou-se em Letras, pela Universidade Estadual do Rio de Janeiro (UERJ); fez Mestrado em Literatura Brasileira, pela UERJ, e Doutorado em Literatura Comparada, pela Universidade Federal Fluminense. Entre seus livros publicados estão 20 poemas para o seu walkman (2007), Engano geográfico (2012), Um teste de resistores (2016), Câmera lenta (2017). Com este último conquistou o primeiro lugar o Prêmio Oceanos de Literatura em Língua Portuguesa, na edição 2018.

Neste artigo abordaremos os poemas "pelos grandes bulevares" e "noite americana", presentes no livro Câmera lenta (2017), a fim de analisarmos como a voz poética é constituída em seus versos, haja vista sua relação com o espaço urbano e com os acontecimentos que circundam esse espaço. Consideramos que a poesia de Marília "realiza-se no limiar das coisas mundanas e das referências de cultura" (FERRO, 2015, p. 136). Dessa forma, objetivamos compreender de que modo os elementos do meio urbano contribuem para a negação de um eu poético a priori, produzindo assim singularidades a partir das vozes que ecoam em seus poemas.

Em linhas gerais, encontraremos na poesia de Marília Garcia uma escrita que parece despoetizar e desmontar aquilo que fora preestabelecido como feminino e poético. Nesse sentido, logo percebemos que seus textos não têm uma preocupação em se demarcar e se reafirmar enquanto escrita feminina. Sua produção poética busca concretizar aquilo que tem sido uma luta das poetas ao longo das décadas: sair da caixinha do que se entende 
ou se espera da poesia dita feminina e produzir uma poesia sem rótulos.

Isto posto, o projeto poético de Marília coloca em xeque os movimentos do meio urbano, predispondo-se a olhá-lo com lentidão, sem a pressa que este meio impõe, mas sem passar despercebida a agitação desse espaço. Outrossim, o fazer poético também é posto em evidência, desde a composição dos versos até a tradução destes, o que dá à produção de Marília um tom de autoficção, ao problematizar questões literárias próprias do seu cotidiano de escritora e tradutora. Sua poesia rejeita o eu ensimesmado, concentrado em si mesmo. Identificamos na poesia de Marília Garcia uma produção de singularidades, na qual o eu está descentralizado, está em movimento para fora..

\section{Análise}

A nosso ver a poesia brasileira contemporânea tem buscado uma escrita que foge do eu apriorístico, daquele eu dotado de uma identidade, uno, homogêneo, mas tem lançado mão de produções de subjetividades, de singularidades, isto é, de multiplicidades que se encontram e se dão na relação com o outro, com o diferente. Corroboramos, pois, com o pensamento de Danielle Magalhães, pois "vemos que nisso está implicado um 'eu' que se coloca em jogo, em risco [...]. Não há, assim, um total apagamento do sujeito, mas um sujeito descentrado, fora de si, excêntrico, que se dá no incessante deslocamento" (MAGALHÃES, 2017, p. 168).

Os lugares de fala, portanto, também são contestados nesse fazer, especialmente aquele relacionado ao aparelho formal da enunciação, proposto por Émile Benveniste (FLORES; 
TEIXEIRA, 2008), quando, ao se referir à noção de pessoa, compreende o $\mathrm{eu}$ como sujeito da enunciação (locutor), o tu como enunciatário (interlocutor), e o ele como aquele de que o $e u$ e o $t u$ falam.

Em contrapartida, vemos que nos poemas estudados neste trabalho todas estas instâncias/pessoas têm possibilidade de fala. $\mathrm{O} e u$ não está mais no centro da enunciação, o tu não existe em dependência de um $e u$, tampouco o ele como elemento que se constitui a partir da relação $e u-t u$. Todos falam à medida que são evocados pela voz poética, a qual também não se configura mais como centro do dizer poético. Desta feita, ao ler a poesia de Marília, não podemos limitar nossa compreensão de que há apenas uma voz poética, mas sim vozes, que, no dizer de Magalhães (2017), não se fazem presentes apenas por meio da escrita, mas sim como potência de voz. Sua poesia é composta por muitas vozes, sejam de personagens, de poetas, de teóricos, as quais emergem como potência, de um fazer que contesta o entendimento do que é poesia, entrando muitas vezes no limiar do gênero ensaístico. Contudo, este é um assunto para outro momento, por ora podemos dizer que sua poesia subverte os modos de ver, escrever, ler e fazer poesia.

Sua poesia faz testes; experimenta palavras, brinca com elas; repensa seu fazer; pondera; arrisca. O movimento de seus versos por vezes sugere o movimento dos pensamentos, quando as ideias surgem de modo desordenado, descontínuo, dos quais surgem reflexões, dúvidas, questionamentos, inquietações: "Retirando-se do lugar de dar respostas, do lugar redentor de garantir uma saída ou um sentido, [...] o posicionamento é pela dúvida [...], pela indefinição, pelas singularidades que se abrem entre os deslocamentos" (MAGALHÃES, 2017, p. 168). 


\section{"Gosto do deslocamento": espaços urbanos e testes de poesia em Marília Garcia}

Outrossim, seus textos evidenciam que sua poesia oscila “entre a repetição e o corte, entre a narrativa e o poema, entre o verso e a prosa, entre o ensaio e a oralidade"; sendo "ao mesmo tempo poema e prosa, ensaio e oralidade, poesia e performance" (MAGALHÃES, 2017, p. 174-175), o que mantém seu texto, segundo Magalhães (2017), em uma zona de indefinição, de suspensão. Diante disso, o leitor se pergunta:

'Que farei agora? Que farei?', o que resta ao leitor senão ‘correr para fora'? Marília Garcia nos convida, então, a percorrer os mapas que constrói, a caminhar por suas perguntas sem respostas, repetições e elucidações em meio a narrativas a princípio desconexas, ir-e-vir de uma linha a outra sem buscar seu ponto de início ou fim (REIS, 2015, p. 289).

É pelo meio que se faz a poesia de Marília. É, pois, pelo meio que devemos lê-la. Afinal, há muitas formas de se começar a ler e/ou escrever um poema, como afirma a voz poética de "Blind light": "poderia começar de muitas formas/ e esse começo poderia ser um movimento ainda sem direção/ que vai se definindo/ durante o trajeto" (GARCIA, 2016, p. 11). É durante o trajeto, em meio ao percurso, que a poesia de Marília Garcia também vai sendo construída. Não encontraremos, portanto, uma linearidade em seu fazer poético, nem sentidos postos, nem respostas prontas, mas a construção de sentido do texto é feita ao longo do caminho. Ler Marília é andar por entre as ruas, é entrar nas entrelinhas do poema para pensar sobre como fora tecido, como fora engendrado, a ponto de nos perguntarmos: isto é poesia?, haja vista que tudo em sua escrita "é ensaio, experimento", afigurando-se "como um dispositivo, um meio, uma ferramenta" (REIS, 2015, p. 289).

A escrita da poeta quebra a todo o tempo com a perspectiva 
do leitor. Quando pensamos estar em um relato pessoal ou mergulhados em uma cena qualquer, logo emergem no poema outras situações que nos levam a outras inferências, impelindonos a refazer os caminhos percorridos até então. Somos instigados a fazer uma nova leitura, pois o texto exige nova interpretação, está carregado de novos sentidos, novos significados que em uma primeira leitura podem passar despercebidos. Assim,

Como uma forma de resistência em teste, portanto, a poesia de Marília se sustenta sobre o risco de si própria, o risco de estar entre, de deixar a dúvida a respeito de seu encaixe em classificações pré-estabelecidas; o risco de se colocar biograficamente como sujeito poético, de citar nomes próprios, lugares por onde passou, de traçar mapas afetivos de maneira escancarada mas que ao mesmo tempo se deslocam e assim sugerem diálogos outros de leitura (REIS, 2015, p. 288-289).

Ao avançarmos na leitura dos poemas, damo-nos conta de que a poesia de Marília é rizomática, à medida que seu texto se horizontaliza, esparramando-se para diversas direções: do ponto de vista estético, a forma como os versos são distribuídos nas páginas; do ponto de vista da escrita, quando um só poema abrange múltiplas situações; do ponto de vista da leitura, ao oferecer vários modos de ler e de interpretar. Podemos aferir que até mesmo o lugar do leitor é desterritorializado e reterritorializado conforme a poeta permite o leitor ser partícipe do seu processo criador.

De modo geral, os poemas de Marília partem de um contexto sociodiscursivo do qual a poeta faz parte, de modo que situações do seu cotidiano de escritora e de tradutora costumeiramente vêm à tona no seu fazer literário. Com isso, não queremos fechar sua poesia na chave da autobiografia, mas sim ressaltar que seu texto é performático, pois "mesmo as referências escancaradas, 
expostas, são capazes ainda assim de deslizar, escapar; de estabelecerem outros diálogos, linhas de fuga, sentidos outros" (REIS, 2015, p. 287).

Em Câmera lenta (2017) deparamo-nos com uma poesia que acontece a partir da dinâmica do olhar, da observação. Cenas são descritas com riqueza de detalhes; seu olhar é lento para perceber situações e descrever ambientes, em contrapartida ao contexto sociocultural contemporâneo, em que o tempo se tornou escasso e as relações pessoais são cada vez mais fluidas e escassas, assim como a relação do homem com o espaço onde vive.

Desta feita, esse modo de olhar, de sentir, de descrever os ambientes e os modos de vida são bastante acentuados no seu livro. Marília nos coloca atrás da câmera e nos faz ver através das lentes muito daquilo que rotineiramente passa despercebido aos nossos olhos. Por vezes somos convidados a olhar em 'câmera lenta'. Contudo, as vozes que ecoam nesse livro não estão aquém, não ficam apenas por trás das câmeras, mas antes participam 'dentro e fora', sendo autores, personagens e cinegrafistas de seus versos.

Assim acontece no poema "pelos grandes bulevares", dividido em dois momentos, ou melhor, em dois lados, o "lado de dentro" e o "de fora". Temos neste poema um eu poético claramente ausente, cuja voz do outro se faz ouvir, bem como o seu modo de ver e de perceber as situações. A voz que ecoa no poema traz o olhar do outro:

[do lado de dentro]

o que ela vê quando fecha

os olhos? linhas sinuosas, um mapa

feito à mão, parece uma pista de cima - 
os campos cortados o verde quando passa

lá no alto.

o que ela vê quando

olha em linha reta tentando

descrever

a garota que conheceu no café?

a transformada de wavelets ou um peixe-lua-

circular em uma região abissal.

não é nada abissal

estar nesta superfície,

você quis dizer de vidro? esférico?

ou um animal marinho em miniatura:

um polvo de $1 \mathrm{~mm}$ ?

o cinema é 24 vezes

a verdade por segundo. este segundo

poderia ser 24 vezes a cara dela

quando fecha os olhos e vê.

(GARCIA, 2017, p. 19).

Nesta primeira parte do poema temos a impressão de estar diante de uma narrativa, cujo narrador é onisciente, pois vê o que se passa na imaginação da personagem. Mas não é possível identificar quem é essa personagem, pois a voz se refere simplesmente a "ela", fazendo uso apenas de um pronome não nomeado (MAGALHÃES, 2017). Nesse sentido, a expressividade da poesia de Marília se apresenta no seu modo de perceber o outro (BUSATO, 2015) e da percepção do outro sobre aquilo que o circunda.

Temos, assim, uma poesia que narra, que não obedece a uma linearidade de acontecimentos; "é toda cheia de arestas, é angulosa, não tem, digamos, um desenvolvimento coerente, linear" (CESAR, 1999, p. 261). Não há, portanto, a sacralização daquilo que caracterizaria um texto como poema: prosa e poesia parecem fazer parte de um mesmo corpo literário.

Isto posto, o texto apresenta-nos aquilo que a personagem 
vê quando fecha os olhos. Observemos que sua percepção imagética acontece em pelo menos dois sentidos visuais, o vertical e o horizontal. Na visão vertical, ela observa do alto, talvez da janela do avião, paisagens, campos, estradas, o que lhe parece como que mapas feitos à mão. Já na visão horizontal, ela verifica as condições de vida de um peixe-lua, uma espécie de peixe que é capaz de sobreviver nas profundezas do oceano, nas regiões abissais, mas também na superfície dos mares, por isso o trocadilho "não é nada abissal/ estar nesta superfície" (GARCIA, 2017, p. 19).

Em contrapartida, outro sentido para a superfície pode ser identificado - superfície de vidro esférico - que cria a ideia de um aquário. $\mathrm{O}$ aquário aparece aqui como uma forma de representação do ambiente subaquático. Considerando-o como um lugar propício à criação de pequenas espécies de peixes, seria impossível criar um peixe-lua, haja vista seu porte físico, chegando a pesar até uma tonelada, bem como criar um polvo de $1 \mathrm{~mm}$, cuja existência nessa dimensão seria bizarra.

Com isso, a poesia de Marília problematiza os modos de se ver e de se apreender a realidade, evidenciando que toda forma de representação é falha e insuficiente. Nesse sentido, o cinema ("o cinema é 24 vezes/ a verdade por segundo") e a imaginação (“o que ela vê quando fecha/ os olhos?") também aparecem na poesia de Marília como formas de representatividade, porém, mais do que defender essas formas, a poeta irá questioná-las.

Dito isto, podemos identificar que a poesia de Marília faz o mesmo movimento dos pensamentos quando apresenta ideias soltas, descontínuas, permeadas e atravessadas por outras ideias; e do cinema, ao buscar captar a mesma imagem por vários ângulos, ampliando-a, distorcendo-a, etc. Nesse ínterim, do 
mesmo modo que um aquário não pode conter um peixe-lua, por exemplo, a poesia também não pode conter a realidade; por outro lado, do mesmo modo que o cinema reproduz 24 vezes mais a verdade, a poesia também é capaz de captar a realidade em diversos sentidos e modos, ampliando-os ou reduzindo-os.

Todavia, da mesma forma como o cinema e a imaginação não são fiéis à realidade, a poesia também não será, nem tem intenção de sê-lo. De certo, o texto de Marília ironiza essa concepção da poesia como forma de representação da realidade, evidenciando que é impossível apreender a realidade, talvez por isso ironize esses modos de representação, os quais são apontados como falhos e imprecisos.

É nessa imprecisão, no entre-lugar, que se encontra a poesia de Marília, talvez por isso o título do poema seja "pelos grandes bulevares", pois caminhar por entre os bulevares é estar no meio, entre duas paisagens, dois modos de ver e perceber, é estar entre o lado de dentro e o de fora. Se na primeira parte do poema, o lado de dentro, somos convidados a adentrar a imaginação da personagem, na segunda parte somos impelidos a abrir os olhos, a abrir a claraboia e perceber o que está do lado de fora. Parafraseando Busato (2015, p. 15), podemos dizer que é a partir do espaço externo, daquilo que fica do lado de fora, que os versos avançam pelo olhar da câmera lenta.

\section{[de fora $]$}

não é por falta de repetição, mas não encontrava a palavra exata.

o que ela vê não sabe e tudo fica tremido se fast forward agora fecha os olhos para entender, para ir mais devagar. 
vezes, era o que achava

mas a essa altura chego no mesmo terminal

duas semanas depois e a cena se

repete.

- você está tendo um problema

de realidade, ele cochichou.

- qual é o desastre desta vez?

o que ela vê ao abrir a

claraboia? ao buscar aquela foto da

ponte ou quando lê

a legenda:

"nos abismos a vida é submetida

ao frio, escuridão, pressão.

oito mil metros de profundidade"

uma montanha

ao contrário.

(GARCIA, 2017, p. 20).

Em contraste com o ritmo dos pensamentos que projetam imagens rápidas e desordenadas, a personagem agora é impulsionada a ver as coisas ao seu redor de maneira lenta, devagar. Aquém da linearidade, o poema apresenta uma cena em que a personagem, aparentemente, se encontra em um terminal e vê alguma cena, não se sabe qual, se repetir. Nesse momento, uma segunda voz, um segundo personagem, aparece no poema; não sabemos de quem se trata, pois é apenas mencionado através do pronome pessoal "ele".

A presença desse segundo personagem enfatiza que a voz do eu poético não está mais no centro do poema, a poesia é espaço agora de vozes despersonalizadas (TIMMER, 2016). Acrescentamos ainda que as múltiplas vozes emergentes na poesia colocam o eu em errância, em ponto de tensão (GARRAMUÑO, 2016), na iminência de "não chegar ao ponto em que não se diz mais eu, mas ao ponto em que já não tem qualquer importância dizer ou não dizer eu" (DELEUZE; GUATTARI, 1995, p. 17). 
Parece-nos que é a esse modo de pensar a poesia contemporânea que se lança a pergunta: "-você está tendo um problema/ de realidade, ele cochichou./ - qual é o desastre desta vez?" (GARCIA, 2017, p. 20), haja vista que a indagação fica suspensa no ar, suspensão esta marcada pela quebra de estrofes, o que até então não ocorrera no poema, já que o texto vinha sendo escrito em estrofe única, a não ser pela quebra que o dividira entre o lado de dentro e o de fora.

Dada esta suspensão, o poema retorna àquilo que a personagem vê ao abrir a claraboia, ao ver uma fotografia, ao observar a profundidade oceânica. Temos aqui 'um problema de realidade', uma realidade distorcida: a região abissal vista como uma montanha ao contrário. Esse modo de enxergar na profundidade a montanha permite-nos entender que também muitas são as possibilidades de ver a realidade. Talvez aí esteja o 'problema de realidade', ou melhor, o problema de representação da realidade. Considerando que há muitos modos de ver e entender a realidade, seria então impossível representála, ou seria essa riqueza de possibilidades o que tornaria possível sua representação?

Entendemos ainda que essa forma contraditória de ver a profundidade oceânica também nos aponta para os modos de feitura da poesia, que pode assumir diversas formas em sua composição, a exemplo dos próprios poemas de Marília Garcia, os quais admitem muitas vezes em sua composição fragmentos de narrativa. Outrossim, não é difícil encontrar na poesia de Marília "procedimentos criativos advindos de outras linguagens artísticas - como o cinema e a fotografia" (SILVA, 2018, p. 312), como acontece no poema "noite americana", em que são descritas três cenas que parecem compor gravações cinematográficas. 
Vejamos abaixo a primeira cena:

noite 1

no momento de maior intimidade

ficaram a $1 \mathrm{~cm}$ de distância

um do outro.

então me afasto e

vejo a cena em câmera

lenta: ali os dois não

se olham.

está escuro e eles atravessam o espaço

o ombro dela quase raspa

o braço dele,

um pouco acima da mão dela.

os dedos dele

os olhos fixos no chão

e a respiração em

compasso.

- por quanto tempo você aguentaria ficar debaixo d'água?

é o que ele parece dizer.

em vez disso, olha o mínimo relógio de pulso

e sabe que seis horas depois já estará

do outro lado.

(GARCIA, 2017, p. 38).

Nesta primeira parte do poema, denominada "noite 1", temos a impressão de estar diante de uma cena romântica, a qual nos é apresentada por uma voz que parece estar atrás da câmera observando e captando cada movimento, como uma espécie de cinegrafista. Temos uma voz que não participa diretamente das cenas que escreve, mas que se coloca como espectador, quase como um narrador-observador.

A voz retrata o encontro entre dois personagens não nomeados, mas que são marcados, assim como em outros poemas de Marília, pelos pronomes 'ele' e 'ela'. Esse encontro, 
entretanto, é marcado pela fugacidade do tempo, metaforizada pela duração de tempo que alguém conseguiria ficar debaixo da água. Não obstante, é imprescindível entender "esses encontros discursivos menos como inscrições no corpo, como marcas indeléveis que vêm de fora para dentro, cujo destino é a permanência, e mais como desprendimentos, que participam de uma singular-pluralidade" (DI LEONE, 2015, p. 133).

Neste primeiro trecho, o desprendimento é marcado pelo atravessamento do espaço, o que confere o deslocamento do sujeito, destituindo assim seu lugar. Esse deslocamento, ora espacial - "está escuro e eles atravessam o espaço" (GARCIA, 2017, p. 38), ora temporal - "está escuro e eles atravessam o tempo" (GARCIA, 2017, p. 39), ora espaço-temporal - "no escuro a luz atravessa o tempo e o espaço" (GARCIA, 2017, p. 40), permeará os três momentos em que o poema está dividido, o que nos permite refletir sobre o lugar que as vozes ou os sujeitos têm assumido na poesia de Marília, um lugar, pois, resvalante, fugidio.

Conforme Di Leone (2015), na poesia de Marília há ecos sem voz original, cujas lembranças e escutas são tão desarraigadas que não sabemos se são do eu do poema ou de outra personagem (DI LEONE, 2015). Assinalamos, ainda, a fala da autora, ao analisar o poema "Olhando a poeira", na qual apresentará aspectos que a nosso ver estão presentes não só no poema em questão, mas no projeto poético de Marília Garcia de forma geral.

[...] no poema não há um sujeito dominador, que acumule esses vestígios, eles nunca constituem um patrimônio: são fulgurações que interpelam, que "terminam com uma pergunta", e se mantêm sem sujeito. Isso, no entanto, não nega a possibilidade de pensar nos sujeitos 
que aparecem no poema como atores [...] (DI LEONE, 2015, p. 133).

Com isso, identificamos que os sujeitos que fazem parte do poema "noite americana" são atores que encenam e protagonizam o fazer poético; a poesia não é mais o lugar do eu poético, por excelência. Na segunda parte de "noite americana", vemos que a voz poética é intercalada por outras vozes, a do personagem (ele) e a de um terceiro sujeito que parece ser a voz do leitor expressando o que sente ao ler os versos da poeta.

noite 2

está chovendo

e quando o farol acende

o verde brilha no escuro.

- claro. escuro. claro. escuro.

(quando você descreve

tenho a impressão de sentir o que

acontece).

um trem parte para um ano

específico no futuro. dizem que lá as coisas

não mudam.

está escuro e eles atravessam o tempo.

me interesso por um único viajante

no trem. ele busca uma noite específica

$\mathrm{e}$, de longe, parece

em repouso invernal.

quando a viagem chega ao fim,

ele decide voltar atrás:

- quando me perguntam

por que voltei, diz ele, nunca dou a mesma resposta.

(GARCIA, 2017, p. 39). 
A cena apresentada na primeira estrofe da "noite 2" é bastante imagética, ao retratar o movimento do farol do carro num dia chuvoso. Ao ler o poema temos exatamente a sensação descrita na terceira estrofe, "a impressão de sentir o que acontece". Como dito anteriormente, essa fala parece ser a voz do próprio leitor. Isso demonstra que o seu lugar, na poesia de Marília, não é apenas o de ouvinte, mas também de ator, de enunciador, que participa e opera no poema.

Ademais, o início desta segunda parte também traz aspectos do espaço urbano, como o trânsito em uma noite de chuva. A importância, porém, desse espaço se dá em virtude dos seus deslocamentos serem ininterruptos (JUSTINO, 2015). Esse movimento, inerente ao meio urbano, é refletido na formação dos sujeitos, assim sendo, podemos dizer que o "sujeito inaugura no poema um espaço discursivo que opera procedimentalmente a imagem do corpo e da voz do(s) sujeito(s) como instâncias da construção do urbano" (BUSATO, 2015, p. 85).

É, pois, a voz, o corpo, os modos de sentir que operam na construção desse espaço, o qual se revela caótico, fragmentado e efêmero, marcado por encontros e desencontros, a exemplo do casal na "noite 1" e do passageiro do trem na "noite 2". Já na "noite 3" há uma quebra de temática, não lemos mais sobre os (des)encontros dos sujeitos, tampouco sobre o espaço urbano. Temos agora um sujeito que se coloca distante das situações, que está fora e observa tudo de longe.

noite 3

a câmera agora

mostra a terra do alto.

de cima,

o planeta azul e úmido 
tem uma única mancha cor

de ferrugem

que fica perto do pacífico.

neste ponto de umidade zero

o ar é tão fino

e tão limpo,

tão frio

e tão seco

que se pode ver com nitidez

a luz dos objetos celestes

vinda do passado.

no escuro a luz atravessa o tempo e o espaço

e vem dar aqui

neste ponto.

em geral, ela se mostra à noite

com as lembranças

em pause.

(GARCIA, 2017, p. 40).

Vale ressaltar que a voz desta terceira parte se confunde com aquilo que é capturado pelas lentes da câmera. Parece-nos que o objeto ganha voz ao descrever, na segunda estrofe, aquilo que suas lentes capturam. Temos a partir de então "o olhar do sujeito como uma câmera" (BUSATO, 2015, p. 90), que não só flagra imagens espaciais, mas sente e é movido por essas imagens, impacta e é por elas impactado.

$\mathrm{Na}$ brevidade de um instante ou na morosidade das lembranças advindas à noite, as cenas são desenhadas "como um flagrante temporal que se espacializa nas figuras da expressão. A poesia nasce desse impacto, da cena e do olhar" (BUSATO, 2015, p. 87-88). Cada parte desse poema se revela como uma cena e cada cena com uma série de fotogramas, os quais não obedecem a uma lógica linear como no cinema, mas são cadenciados de forma a dar movimento ao texto. 
Somos, assim, colocados atrás da câmera e por ela assistimos às cenas que surgem ora em pause ora em movimento, cenas que se intercalam, que convergem, que divergem e que em algum momento ou em outro se complementam. Por meio dessas interações, corroboramos com Reis (2015) ao defender que a poesia de Marília acontece a partir das relações e dos diálogos que pode estabelecer, bem como das tensões entre as diferentes linguagens, sejam estas literárias ou não. Desse modo, corroboramos com Silva (2018) ao identificar que o projeto poético de Marília testa as possibilidades e os limites da linguagem poética, ao mesmo tempo em que suscita a participação do leitor nesse projeto.

\section{Conclusão}

A poesia de Marília Garia subverte o modo de ver, entender, escrever, ler e fazer poesia. Em seus textos a poeta faz testes, experimenta palavras, significados, (re)pensa seu fazer, pondera, arrisca. Os espaços urbanos, por exemplo, são uma marca bastante recorrente nos seus poemas, bem como o modo como os sujeitos se relacionam com e nesses espaços. A hibridez de cenas e imagens permeiam sua poesia, permitindo-nos ver e sentir aquilo que descreve. Por vezes somos colocados nas cenas, atuando não como meros espectadores, mas como coadjuvantes do seu fazer poético.

Os acidentes do caminho, as situações do cotidiano, a fala do outro são alguns elementos recorrentes em sua poesia. As vozes que emanam em seus textos parecem pairar diante da cidade para observar o movimento das pessoas, do trânsito, as construções civis que compõem o espaço urbano, a agitação de 
metrópoles, como São Paulo. Mas seu olhar é lento, observa as situações em modo câmera lenta, às vezes em modo pause, em ritmo desacelerado. Porém, essas imagens ganham velocidade ao serem descritas, são ditas rapidamente, haja vista a ausência de pontuação em seus poemas, o que sugere a pressa da sociedade contemporânea.

Os sujeitos circunscritos na poesia de Marília leem e sentem o pulsar da cidade com os sentidos: seja sentindo o sabor de um crepe, o cheiro da poeira, as sensações térmicas causadas pelas condições climáticas, ouvindo o barulho dos carros, percebendo as mudanças que acontecem nas edificações das cidades, etc.

As situações pelas quais passam esses sujeitos se confundem frequentemente com aspectos autoficcionais, em que situações da vida da poeta emergem no enredo do poema. Entretanto, embora a autoficção faça parte de seu fazer poético, a voz autoficcionalizada não se enclausura em si mesma, mas reúne outra vozes, de poetas, de personagens, etc. Há, portanto, em sua poesia, um eu descentralizado, atravessado por pensamentos e dizeres de outros sujeitos.

\section{Referências}

BUSATO, Susanna. O espaço urbano como construção poética do sujeito. Estudos de Literatura Brasileira Contemporânea, Brasília, v. 45, p.85-101, jun. 2015. Disponível em: http://dx.doi. org/10.1590/2316-4018455 Acesso em: 05 dez. 2019.

CESAR, Ana Cristina. Crítica e tradução. São Paulo: Ática, 1999.

DELEUZE, G.; GUATTARI, F. Mil platôs. Vol. 1. Tradução de Ana Lúcia de Oliveira, Aurélio Guerra Neto, Célia Pinto Costa. 
São Paulo: Editora 34, 1995.

DI LEONE, L. Olhando a poeira: o método e a poesia de Marília Garcia. In: SCRAMIM, Susana; SISCAR, Marcos; PUCHEU, Alberto. O duplo estado da poesia: modernidade e contemporaneidade. São Paulo: Iluminuras, 2015, p. 125-134.

FERRO, L. C. S. Paisagens em profusão: as poéticas contemporâneas de Angélica Freitas, Fabiano Calixto, Marília Garcia e Ricardo Domeneck. 2015. 258 f. Tese (Doutorado em Letras e Linguística) - Universidade Federal de Goiás, Goiânia, 2015. Disponível em: http://repositorio.bc.ufg.br/tede/handle/tede/5156 Acesso em: 30 ago. 2019.

FLORES, V. N.; TEIXEIRA, Marlene. Introdução à linguística da enunciação. São Paulo: Contexto, 2008.

GARCIA, M. Um teste de resistores. $2^{\mathrm{a}}$ ed. Rio de Janeiro: 7 letras, 2016.

GARCIA, M. Câmera lenta. São Paulo: Companhia das letras, 2017.

GARRAMUÑO, F. A poesia contemporânea como confim. In: SCRAMIM, S.; SISCAR, M.; PUCHEU, A. (org.). Linhas de fuga: poesia, modernidade, contemporaneidade. São Paulo: Iluminuras, 2016, p. 11-17.

JUSTINO, L. B. Literatura de multidão e intermidialidade: ensaios sobre ler e escrever o presente. Campina Grande: Eduepb, 2015.

MAGALHÃES, D. A poesia como um teste de resistores. Revista Escrita, Rio de Janeiro, n. 23, p.160-176, ago. 2017. Disponível em: https://doi.org/10.17771/PUCRio.escrita.31110 Acesso em: 2 out. 2019.

REIS, J. T. A palavra iminente de Marília Garcia. SEMINÁRIO DOS ALUNOS DOS PROGRAMAS DE PÓS-GRADUAÇÃO DO INSTITUTO DE LETRAS DA 
UFF ESTUDOS DE LITERATURA, 6., 2015, Rio de Janeiro. Estudo de literatura. Rio de Janeiro: Uff, 2015, p. 283-291. Disponível em: http://www.anaisdosappil.uff.br/ index.php/VISAPPIL-Lit/article/view/369 Acesso em: 30 out. 2019.

SILVA, A. C. Marília Garcia: para onde nos levam as hélices do poema?. Estudos de Literatura Brasileira Contemporânea, Brasília, n. 55, p.309-323, dez. 2018. Disponível em: https://doi. org/10.1590/10.1590/2316-40185516 Acesso em: 01 set. 2019.

TIMMER, N. Ilhas, roteiros e diáspora(s): poesia cubana pósnoventa. In: SCRAMIM, S.; SISCAR, M.; PUCHEU, A. (org.). Linhas de fuga: poesia, modernidade e contemporaneidade. São Paulo: Iluminuras, 2016, p. 19-30. 